\title{
73. SECULAR PERTURBATIONS ON THE MINOR BODIES OF THE SOLAR SYSTEM
}

\author{
I. V. GALIBINA \\ Institute for Theoretical Astronomy, Leningrad, U.S.S.R.
}

By means of the Gauss-Halphen-Goryachev method secular orbital variations have been studied for a period of $4000 \mathrm{yr}$ (from -50 to +3950 ). The method has been applied to the periodic comets Halley, Brorsen-Metcalf, Pons-Brooks, Westphal, Olbers, Neujmin 1, and Encke. Investigations have demonstrated that the use of the method for most comets is not expedient as it does not allow for the possibility of approaches to the major planets and thus does not reflect the real evolution of the cometary orbits. Application of the method over the interval of 2000 years back from the epoch 1950.0 for the planets 279 Thule, 1162 Larissa, 1180 Rita, and 1202 Marina, as well as from the epoch 1850.0 for 1 Ceres has given adequate results and has displayed the stability of these orbits. Study of the secular perturbations on the Leonids over the interval of $4000 \mathrm{yr}$ has confirmed the stability of that meteor stream. By means of the same method 14 minor meteor streams were investigated, and their orbits also proved to be stable. The availability of the various systems of osculating elements has permitted us to estimate for the first time the possibility of the encounter of those streams with the Earth over a 4000-yr period. For further details see Galibina (1970a, 1970b, 1971).

\section{References}

Galibina, I. V.: 1970a, Byull. Inst. Teor. Astron. 12, 261.

Galibina, I. V.: 1970b, Byull. Inst. Teor. Astron. 12, 470.

Galibina, I. V.: 1971, Byull. Inst. Teor. Astron. 12, 870.

\section{Discussion}

B. G. Marsden: Two of the objects you have studied, P/Neujmin 1 and 279 Thule, are involved in librations about resonances with Jupiter. A purely secular treatment may thus yield results that are considerably in error. Is there a possibility that you could allow for these resonant effects in your calculations?

I. V. Galibina: I have not done so.

F. L. Whipple: What initial elements were adopted for $\mathrm{P} /$ Encke and which planetary perturbations were taken in account?

I. V. Galibina: The 1961 elements were adopted and the perturbations by Jupiter, Saturn, Uranus, and Neptune were considered.

$V$. V. Fedynskij: You have stressed the stability of meteor streams. The physical nature of meteoroids is not taken into account, however, and because of the Poynting-Robertson effect their lifetimes are much shorter than the interval over which their stability has been studied. This is especially relevant for small particles. I should like to suggest that in future the possibility of allowing for these nongravitational effects be investigated.

B. Yu. Levin: I do not agree that the lifetimes of the particles are so short. Consideration of the Poynting-Robertson effect will not appreciably influence the lifetime of a particle.

$F$. L. Whipple: The lifetime of a meteoroid is a few thousand years, comparable with the period covered by the investigation. 